\title{
CHALLENGES FOR THE ROMANIAN SMEs ON THE LABOUR MARKET
}

\author{
Mădŭlina Ecaterina POPESCU ${ }^{a *}$, Amalia CRISTESCU ${ }^{b}$, Ana-Maria GATEA $^{c}$ \\ $a, b$, Bucharest University of Economic Studies, Romania \\ ${ }^{c}$ National Scientific Research Institute for Labour and Social Protection, Romania
}

DOI: $10.24818 / \mathrm{IMC} / 2020 / 03.02$

\begin{abstract}
This paper aims to investigate how companies react to various changes in fiscal and wage policies. Empirical evidence is provided for the case of Romania, using quantitative statistical analysis on survey data. The survey was conducted in November 2019 by the National Scientific Research Institute for Labour and Social Protection upon around 1200 Romanian SMEs. Through this paper, we show how companies reacted to the legislative changes that took place at the beginning of 2018, the most important being the increase of the minimum wage, the transfer of social contributions from employer to employee and the reduction of income tax from 16\% to 10\%. Finally, we share some insights about potential challenges the business environment might be facing in the near future.
\end{abstract}

KEYWORDS: minimum wage, fiscal policy, SMEs strategies, personnel changes, business environment

\section{INTRODUCTION}

Fiscal and wage policies can represent a major hurdle for the structural evolutions of any company, especially when they are not correlated to the evolution of other macro and microeconomic variables. Evidently, each company's goals and structure are indirectly impacted by any fiscal or wage pressure, which may lead to a series of changes in business behaviour. Companies will seek to find and apply a number of strategies to better coupe with the economic instability.

Labour market reforms can raise tax costs - either directly, by changing taxes or unemployment benefits, or indirectly, by using tax compensation to reduce the distributional effects of the reform (IMF, 2014). Evidently, raising salaries at the level of firms must be sustainable, generated through productivity, so that the actual workforce cost dynamic does not exceed the actual productivity dynamic, due to wage increases in nominal terms, which would result in rising market prices and potentially cause a wage compensation effect in real terms.

Having this into consideration, the aim of the paper consists in investigating how companies react to changes in the fiscal and wage policies. Empirical evidence for the case of Romania is provided using quantitative statistical analysis on survey data. The survey was conducted in November 2019 by the National Scientific Research Institute for Labour and Social Protection (INCSMPS) upon around 1200 Romanian SMEs.

In order to study the behavior of Romanian companies due to changes in the fiscal and wage policies, we designed a questionnaire that could allow us to investigate both the strategies taken by firms to deal with minimum wage increases and the main challenges the companies are currently facing due to the latest fiscal and wage policy changes. We mainly refer to how companies reacted to the legislative changes that took place at the beginning of 2018 in Romania, the most important

\footnotetext{
*Corresponding autor: E-mail address: madalina.andreica@csie.ase.ro
} 
ones being the increase of the minimum wage, the transfer of social contributions from employer to employee and the reduction of income tax from $16 \%$ to $10 \%$. Finally, we share some insights about potential challenges the business environment might be facing in the near future.

The novelty of the paper consists in providing recent insights into the Romanian business environment and on how the SMEs react to various changes in fiscal and wage policies. Even though the study can only provide insights for a single country and a given period of time, we believe it brings added value to the current literature in the field, not only by providing some general conclusions on how companies react to fiscal and wage policies, but also because such information could be informative for policy design.

The paper is structured as follows. Section 2 presents a short literature review regarding the empirical evidence concerning companies' reaction to changes in the fiscal and wage policy, while Section 3 is dedicated to the description of the data and methodology. Finally, last section concludes.

\section{LITERATURE REVIEW}

Recently there has been an increasing interest in the European Union on how companies adjust to changes in fiscal and wage policies. This is especially explainable for the case of developing countries, on the one hand, due to the current recommendation from the European Commission towards having a minimum wage setting mechanism implemented, and on the other hand, due to the current economic instability that requires effective fiscal policy adjustments. Moreover, Horemans et al. (2016) argues that in developing countries it is more likely for the minimum wage growths to have stronger impact on the labour market, as compared to other E.U. countries. Since in Central and Eastern European countries wages are typically lower, it can partially explain the relatively high incidence of poverty among employed people and the labour market segmentation in these countries.

The empirical studies on this topic in the literature review are mainly focused either on the management strategies taken by firms to deal with minimum wage increases or on the main challenges the companies are facing due to latest fiscal and wage policy changes. For instance, Bodnar et al. (2018) investigated the minimum wage transmission channels for eight E.U countries, among which some were developing countries (namely Bulgaria, Hungary and Romania). According to their study, among the main strategic decisions taken by companies to adjust to minimum wage increases are layoffs, fewer new jobs created, price increases and drops in nonwage costs in order to increase productivity.

Moreover, companies have to decide the strategy to readjust its own employees wage policy scheme, having to choose between a proportional wage increase for all employees, a wage increase just for the employees earning below the new minimum wage level, or a wage increase for both minimum wage earners and for those just above the minimum wage level.

For the case of Romania in particular, the report of Iordache et al. (2016) provides a detailed analysis of the factors that did not allow the post-crisis economic recovery in Romania to also be accompanied by a similar boost of the labour market. The analysis starts from a data set obtained at microeconomic level through a survey that was conducted in 2014 by the National Bank of Romania in cooperation with the Wage Dynamics Network (WDN). Another recent online survey on Romanian SMEs was conducted in 2018 by the National Romanian Council for Small and Medium Private Enterprises (2018). It investigated how a raise in the minimum wage affects the business environment. Finally, in terms of minimum wage policy setting in Romania, the paper of Popescu et al. (2017) is worth mentioning as a first attempt to design a minimum wage-setting mechanism at national level. The paper identifies both potential indicators that can be used for indexation of the minimum wage level and criteria for impact assessment on the labour market and the business environment. 


\section{DATA AND METHODOLOGY}

In order to study the behaviour of Romanian companies due to changes in the fiscal and wage policies, a quantitative statistical analysis was performed based on survey data. The survey was conducted in November 2019 by the National Scientific Research Institute for Labour and Social Protection (INCSMPS) upon around 1200 Romanian SMEs. The survey sample was nationally representative, being extracted with the sampling error of $+/-3 \%$ at a confidence level of $95 \%$. The data collection was performed through a mix of methods, consisting of CAWI (Computer Aided Web Interview), CATI (Computer-assisted personal interview) and also Face-to-Face.

The sample was stratified, in relation to the following criteria: enterprise's size (less than 9 employees; between 10-49 employees; between 50-249 employees; over 250 employees), development region, main field of activity of the enterprise and turnover level. Both urban and rural areas were considered when randomly selecting the sample of SMEs.

In order to investigate how Romanian companies have adapted to changes in the wage and fiscal policies that took place mainly in 2018, we designed a questionnaire structured in five sections. The first section consisted in companies' identification data, the second section focused on company's own wage policy, followed by a section dedicated to the effects of the recent minimum wage increase and on how companies responded to such economic changes. Section 4 investigated the effects of recent fiscal policy changes, while the last section collected financial indicators from the last two years of firms' activity. Following Bodnar et al. (2018) approach, the questionnaire included questions regarding not only the main strategies to adjust to a minimum wage increase, but also the proportion of minimum wage employees of each firm.

Table 1 shows the distribution by economic sectors of the firms included in the sample. It can be noticed that over one third of them operate in Trade, 13\% in Professional, scientific and technical activities and $10 \%$ in Construction. Transportation and storage represents $9 \%$ of the sample, as does Industry, while Information and communication and Accommodation and food services activities are both at 5\%. Lower percentages can be observed for the sectors of Human health and social work activities, Real estate activities and Agriculture, forestry and fishing, with 3\% each. Arts, entertainment and recreation and Financial and insurance activities form $2 \%$ each and only $1 \%$ of firms are classed in the Education sector.

Table 1. SMEs distribution on economic sectors

\begin{tabular}{|l|c|}
\hline Economic sector & $\begin{array}{c}\text { Percent of } \\
\text { the sample } \\
\text { size }\end{array}$ \\
\hline Trade & $34 \%$ \\
\hline Professional, scientific and technical activities & $13 \%$ \\
\hline Construction & $10 \%$ \\
\hline Industry & $9 \%$ \\
\hline Transportation and storage & $9 \%$ \\
\hline Information and communication & $5 \%$ \\
\hline Accommodation and food services activities & $5 \%$ \\
\hline Human health and social work activities & $3 \%$ \\
\hline Real estate activities & $3 \%$ \\
\hline Agriculture, forestry and fishing & $3 \%$ \\
\hline Arts, entertainment and recreation & $2 \%$ \\
\hline Financial and insurance activities & $2 \%$ \\
\hline Education & $1 \%$ \\
\hline
\end{tabular}

Source: authors’ computation 
The sample's distribution by economic sectors is consistent with the general structure by main economic sector (NACE Rev.2) of the total population of Romanian companies. The sampling by economic sectors is within the error limits, with the exception of the slightly lower percentage of firms in the Trade sector (due to firms' identification issues in this highly dynamic area of activity). In relation to the place of residence, $84.4 \%$ of the companies were randomly selected from urban areas and $15.6 \%$ from rural areas. However, representativeness is much more balanced at a regional level. A slightly higher percentage of firms (25\%) were selected from the Bucharest-Ilfov region. The remaining 7 development regions were closer in range - North-West with $15 \%$, Centre with $12 \%$, North-East, South and South-East with 11\% each, West with 9\% and South-West with 7\%.

\section{MAIN FINDINGS}

\subsection{Structure of the personnel scheme}

The selected sample is formed by small and medium sized enterprises (SMEs), as can be seen by the number of permanent and temporary jobs within the firms. A percentage of $88.3 \%$ of the companies have fewer than 9 permanent or temporary employees and $9.6 \%$ have between 10 and 49 employees. Only $1.8 \%$ of the companies have between 50 and 249 employees and $0.3 \%$ employ over 250 individuals. The sampling by size category was related to the parameter provided by the National Institute of Statistics regarding enterprise size categories for the year 2017. At the same time, the category of fewer than 9 employees was reduced, while the other categories were augmented so that processing by subcategories could be more accurate.

The proportion of employees hired on a temporary basis or with a fixed-term employment contract is rather low (see Figure 1). Among the companies with fixed-term employment contracts, 3\% of them declared that those make up less than $15 \%$ of all contracts, $11 \%$ said that they represented between $15 \%$ and $30 \%$ of all contracts and $3 \%$ stated that fixed-term employment contracts make up between $30 \%$ and $50 \%$ of all contracts in their firm.

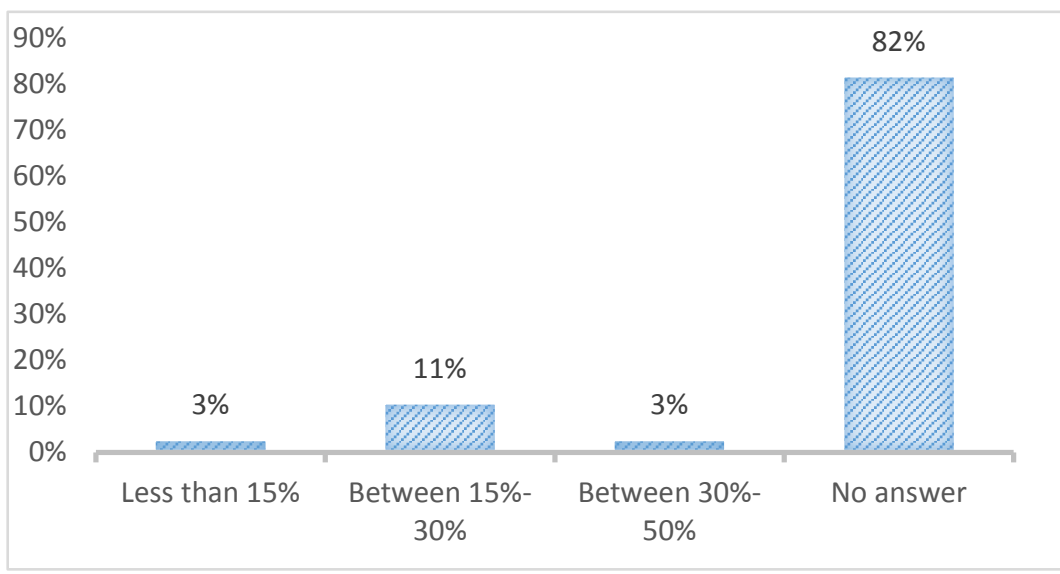

Figure 1. The percent of fixed-term employment contracts

Source: authors' computation based on survey data

This reflects the current situation at national level in Romania. According to Eurostat, the percentage of fixed-term employment contracts across the European Union in 2019 was 13.6\% of all employment contracts. The countries with the lowest shares of fixed-term employment contracts were Romania and Lithuania, both being 1.5\% of all employment contracts.

By looking at the average number of minimum wage employees (see Figure 2) we notice that over half of them have between 1 and 3 employees and a quarter have between 4 and 6 employees. The percentage of companies with 7 employees is lower. Companies with 7-10 minimum wage 
employees amount to 6\% in 2017 and $8.4 \%$ in 2018. The share of companies with over 10 minimum wage employees was $14.2 \%$ in 2017 and $12.6 \%$ in 2018.

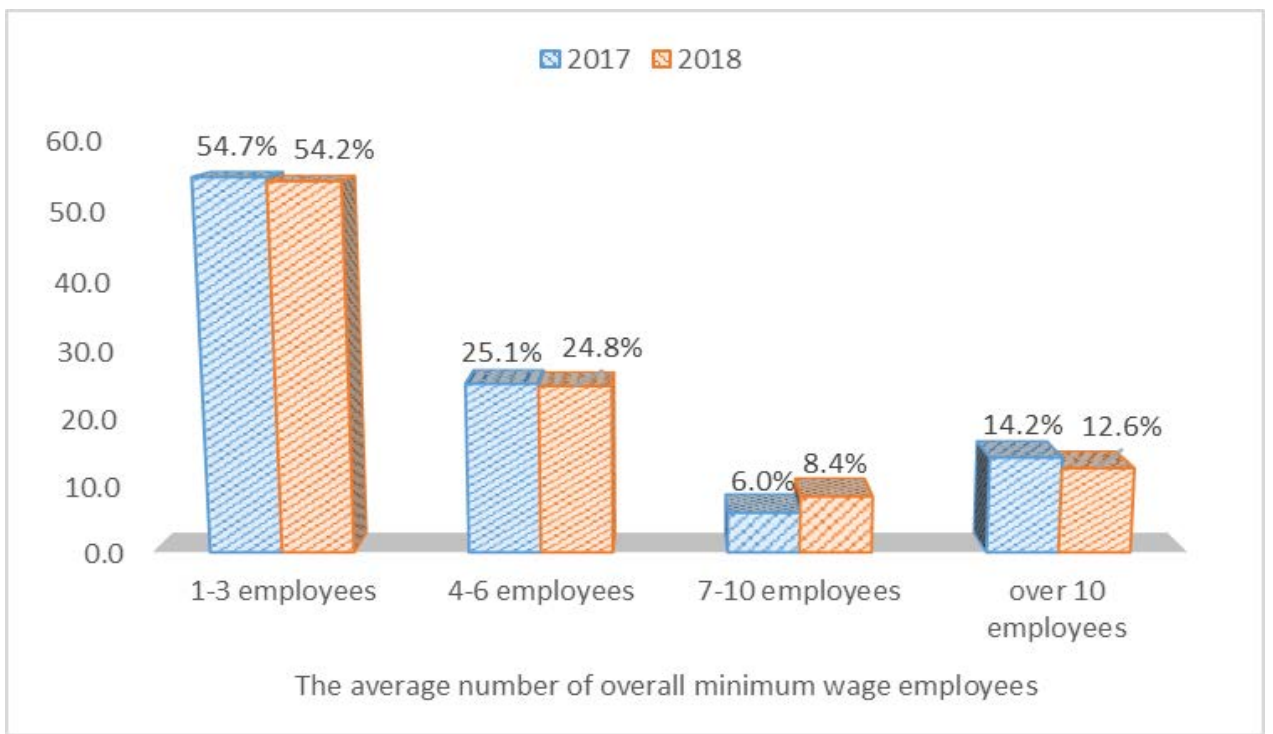

Figure 2. The average number of minimum wage employees in 2017 and 2018 (before and after the increase of the minimum wage from 1450 lei to 1900 lei)

Source: authors' computation based on survey data

The raising of the minimum wage on January the $1^{\text {st }} 2018$ from 1450 lei to 1900 lei does not seem to have had much of an impact on the average number of minimum wage employees for companies overall. This can be explained through the fact that the $31.03 \%$ increase in the minimum wage was also influenced by the transfer of social contributions from employer to employee in a proportion of $22.75 \%$. Under such circumstances, the actual increase was lower. In the case of companies who declared having minimum wage employees, we can notice that after the increase of the minimum wage the percentage of companies with 1-6 minimum wage employees decreased, while the one of companies with 7-10 minimum wage employees increased. A slight decrease (of 1.57 percentage points) was also noted in the share of companies with over 10 minimum wage employees. We could argue that companies did not adjust to the increase of the minimum wage, so that the number of minimum wage employees overall increased. Some companies which were paying their employees a gross salary of 1900 lei did not raise those salaries, so that employees were now at the level of the new minimum wage and the number of minimum wage employees increased.

A significant share of the surveyed companies (78.6\% in 2017 and $73.9 \%$ in 2018) with 1-3 minimum wage employees stated that those employees were women. Of those companies with 4-6 minimum wage employees, $10.8 \%$ in 2017 and $10.7 \%$ in 2018 stated that those employees were women. At the same time, a high percentage of companies with 1-3 minimum wage employees, stated, both in 2017 (80.4\%) and in 2018 (74.4\%), that those employees were under the age of 25 . Higher percentages of companies employing young people on minimum wage can be seen for companies with over 10 minimum wage employees - 12.8\% in 2017 and $14.9 \%$ in 2018.

To conclude, we can say that over half of the surveyed companies have between 1 and 3 minimum wage employees, the majority of whom are young women under the age of 25. This finding is supported by the fact that a third of the surveyed companies operate in the trade sector, where commonly women form a majority and wages are lower. 


\subsection{Strategies to adapt to changes in wage and fiscal policy}

Over half of the surveyed companies (54\%) described their financial situation as good and 10\% even considered to be very good. However, a third (29\%) of the companies characterised their financial situation in 2019 as bad and 8\% stated it to be very bad.

Reactions to the fiscal and/or wage policy changes can also differ among companies based on their financial situation. In the case of the increase of the minimum wage, correlations of the survey data showed that, regardless of financial situation (good or bad), most companies (over 60\%) chose to proportionally raise all the wages in the company. Raising only the salaries below the new minimum wage threshold was done by $27 \%$ of the companies with a good or very good financial situation and by $32 \%$ of the companies with a bad or very bad financial situation. Only $8 \%$ of the surveyed companies with a good or very good financial situation and $7 \%$ of companies with a bad or very bad financial situation also raised the salaries of employees earning more than minimum wage. As such, in the case of raising the minimum wage, we can observe that although companies tend to proportionally raise all wages, regardless of financial situation, companies with a bad or very bad financial situation are more likely to only raise the salaries found under the minimum wage threshold.

Regarding the level of the minimum gross salary of 2080 lei in 2019, a majority of the companies (80\%) consider that this does not represent a hindrance in the way of hiring young people. A share of $11.9 \%$ of the companies did not answer or did not know how to answer this question and only $8.1 \%$ considered that a minimum wage of 2080 would have a negative influence on the hiring rates for young people in their companies. We could therefore argue that factors such as lack of experience/qualification and lack of seriousness are more of an obstacle for hiring young people than the level of the minimum wage.

Regarding the causes that led to staff fluctuations in 2018 (see Figure 3), we observe that, in the case of companies with a good or very good financial situation, the most frequent reasons given were tied to wages within the company being too low compared to those of the competition (61\%), labour taxation being too high (43\%), failure of staff to perform work tasks (39\%) and staff dissatisfaction with the non-wage incentives received (32\%).

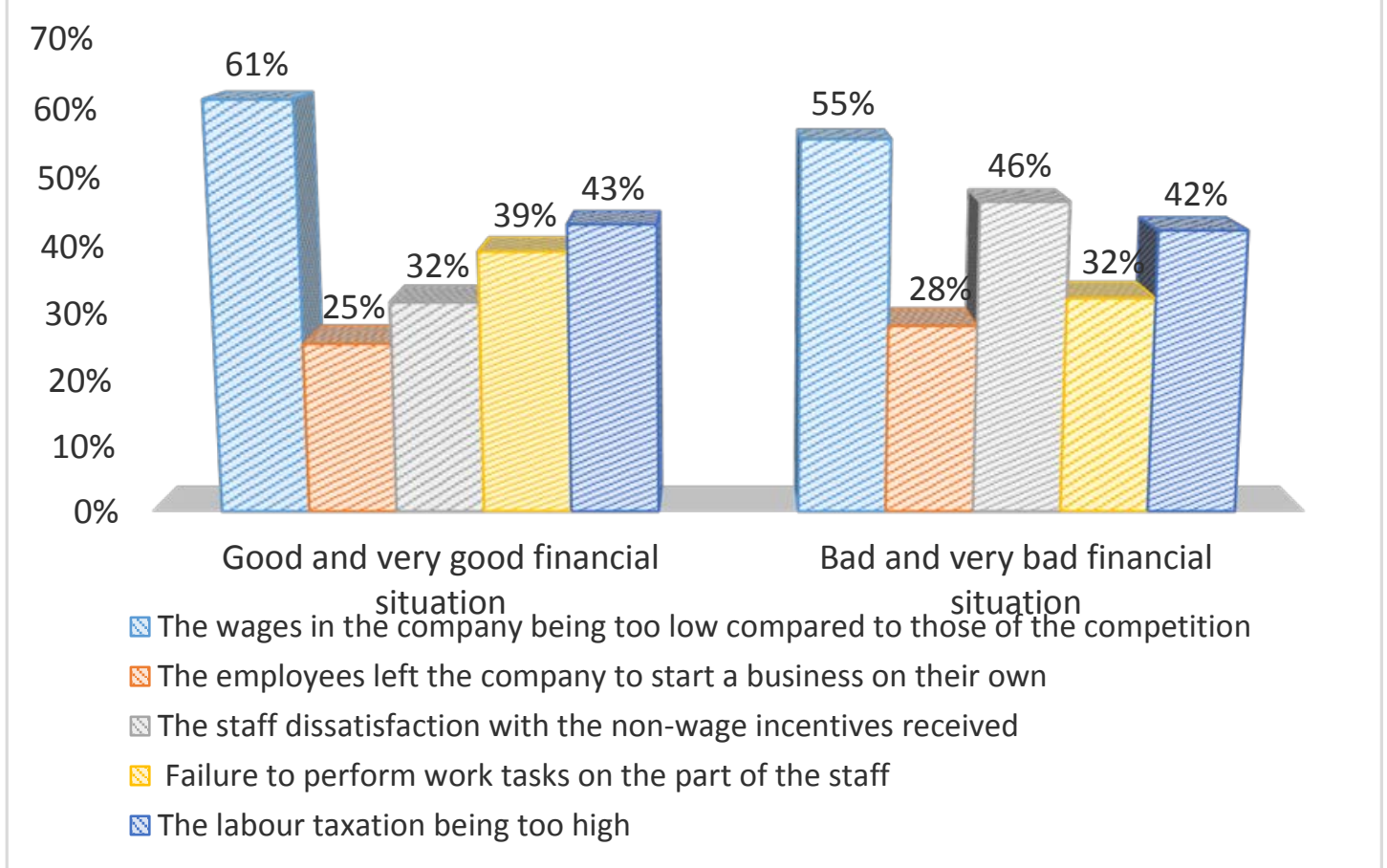

Figure 3. Causes of staff fluctuation in $\mathbf{2 0 1 8}$ according to financial situation Source: authors' computation based on survey data 
In case of companies with a bad or very bad financial situation, the most frequent factor considered to have caused staff fluctuation is tied to wages within the company being too low compared to those of the competition (55\%). Another cause mentioned by $46 \%$ of the companies with a bad or very bad financial situation is staff dissatisfaction with the non-wage incentives received. Similarly to companies with a good or very good financial situation, $42 \%$ considered that labour taxation being too high constituted a cause for staff fluctuations in 2018.

Regardless of the financial situation, it can be noticed that the primary cause for staff fluctuation in 2018, for the surveyed companies, was tied to the fact that they were paying lower wages compared to their competitors.

\subsection{Potential challenges for the business environment}

Without taking into account the effects of the COVID-19 pandemic, which was triggered a couple of months after the completion of the survey on SMEs, companies believe that the most delicate situation they would likely encounter in 2020 would be finding qualified staff for hiring (68.4\%). Over half of the surveyed companies considered that another issue might be workforce costs rising faster than the raw materials costs or the capital (57.5\%), which would also lead to difficulties in paying wages (53.6\%). At the same time, an increase in the minimum wage over the inflation growth might affect $46.6 \%$ of companies. As can be noted, at the time that the survey took place (2019), situations most companies believed might impact their activity were predominantly tied to finding qualified staff to hire, followed by issues related to growing workforce costs and difficulties in paying wages. Lack of trained staffed showed to be a more pressing issue than the raising of wages (see Figure 4).

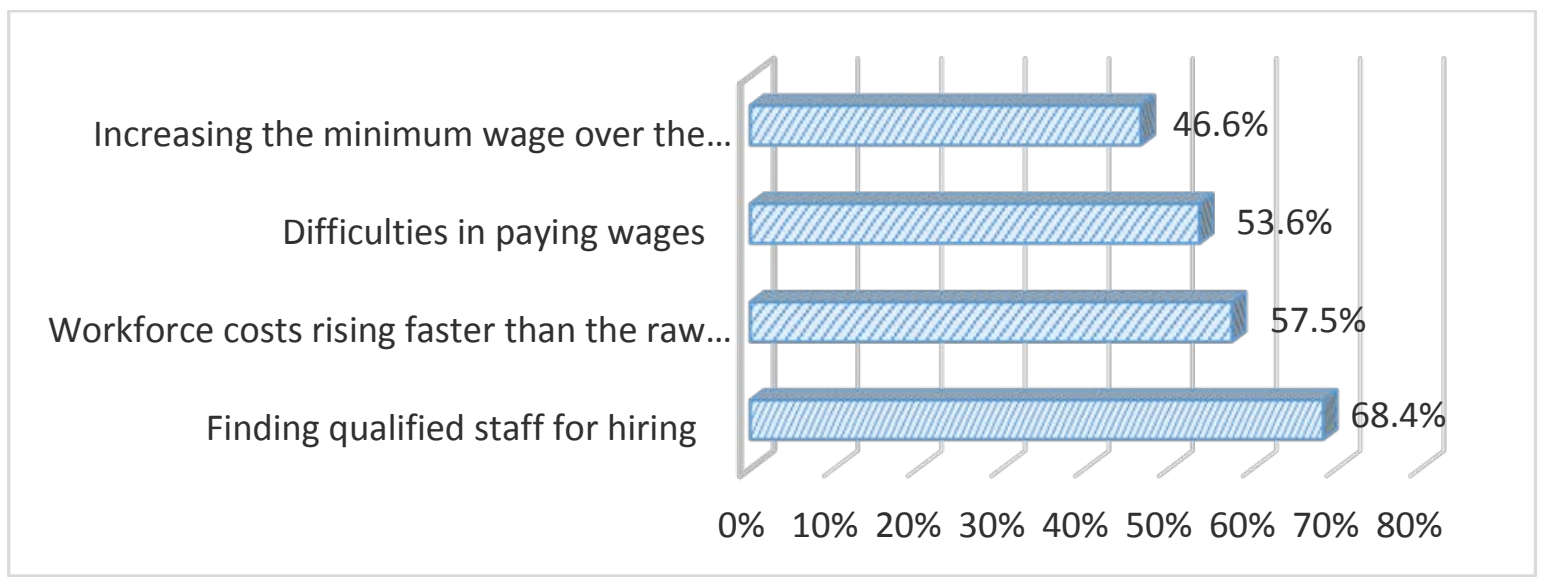

Figure 4. Possible situations companies could face in 2020

Source: authors' computation based on survey data

The launch of a new taxation system could directly impact companies' activity. In this scenario, especially as a result of the public debates regarding the introduction of a progressive taxation system, the companies were also asked to what degree such a system might impact their activity.

According to Figure 5, we note that $35.8 \%$ of the surveyed companies claim that a progressive taxation system could sustain their activity to a small degree, while $17.5 \%$ say to a very low degree. At the same time, a quarter of the companies (24.6\%) believe that a progressive taxation system could sustain their activity to a large degree and $10.5 \%$ say it could sustain it to a very large degree. There is also a share of $11.6 \%$ who did not answer or did not know how to answer the question, which points to the fact that some companies are not familiar with the taxation system or with its effects on their business. 


\title{
Figure 5. The degree to which the introduction of a progressive taxation system (compared to the current single labour tax rate of $10 \%$ ) could sustain company activity
}

\author{
Source: authors' computation based on survey data
}

Clearly, in 2018 a series of legislative changes took place, which also impacted the entrepreneurial environment, the most important being the increase of the minimum wage, the transfer of social contributions from employer to employee, the reduction of income tax from $16 \%$ to $10 \%$, but also contribution rate to the pension Pillar II, from 5.1\% to 3.75\%. We could argue that the increase to the minimum wage was somewhat compensated though some measures means to reduce company expenses, which is why company spending remain unchanged or only registered small decreases.

\section{CONCLUSIONS}

In the current economic context, when economic recovery and recovery of development gaps are major economic objectives for Romania, the minimum wage and the fiscal policy measures impact the labour market and the entrepreneurial environment. Thus, these issues should be approached in a systemic and complex manner, taking into account social aspects, such as the side of domestic demand, the supply of goods and services, as well as the short, medium and long-term impact on macroeconomic indicators.

Through this survey-based analysis on Romanian companies, we tried to show how companies behaved and reacted following the legislative changes that took place at the beginning of the year 2018, the most important being the increase of the minimum wage, the transfer of social contributions from employer to employee and the reduction of income tax from $16 \%$ to $10 \%$.

Companies stated their financial situation as good or very good in $64 \%$ of the cases, while the remaining 36\% considered their financial situations to be bad or very bad.

Without considering the effects of the COVID-19 pandemic, for the year 2020, the most delicate situation they would likely encounter would be finding qualified staff for hiring. Over half of the surveyed companies considered that another issue might be workforce costs rising faster than the raw materials costs or the capital and implicitly the difficulty of paying wages. At the same time, an increase to the minimum wage over the inflation growth might affect $46.6 \%$ of companies.

Certainly, there is a substantial link between companies' activity, economic growth and national progress, and public fiscal and wage policies can have a decisive impact on the how entrepreneurial activities are carried out. Entrepreneurs believe that the most important hurdles in the way of their businesses growth are more often related to public policies or to factors controlled by state institutions: fiscal and legislative uncertainty, political instability, lack of vision in areas of public policy and bureaucracy. In this situation, our study wants to highlight the way in which Romanian companies react to certain fiscal and wage policy measures. Usually, any public policy decision 
which impacts the entrepreneurial environment should be made after rigorous consultations and after some investigations have been made into the impact of the measure on most of the affected companies.

\section{ACKNOWLEDGMENT}

This work was supported by the NUCLEU Program funded by the Romanian Ministry of Research and Innovation (Project PN 19130103).

\section{REFERENCES}

Bodnar, K., Fadejeva, L., Iordache, S., Malk, L., Paskaleva, D., Pesliakaite, J. et al. (2018). How do firms adjust to rises in the minimum wage? Survey evidence from Central and Eastern Europe. IZA Journal of Labour Policy, 7(11).

Horemans, J., Marx, I. \& Nolan, B. (2016). Hanging in, but only just: part-time employment and inwork poverty throughout the crisis. IZA Journal of European Labor Studies.

International Monetary Fund (2014). Can fiscal policies do more for jobs?. Washington D.C.

Iordache, Ș. C., Militaru, M. \& Pandioniu, M. L. (2016). Jobless recovery in Romania: the role of sticky wages and other frictions: firm-level evidence from the WDN survey. National Bank of Romania - Caiete de studii, 44, 5-56.

Popescu, M. E., Militaru, E., Pele, D., Mazurencu Marinescu, M., Vasile, V., Ilie, S., et al. (2017). Support for establishing a minimum wage-setting mechanism in Romania. Iași: LUMEN Publishing.

The National Romanian Council for Small and Medium Private Enterprises (2018). Testul IMM privind creșterea salariului minim pe economie de la 1.900 lei la 2.080 lei si la 2.350 lei. Retrieved September 15, 2020, from http://cnipmmr.ro/2018/11/26/testul-imm-privindcresterea-salariului-minim-pe-economie-de-la-1-900-lei-la-2-080-lei-si-la-2-350-lei/ 